\title{
EL FATAL KAFKA Y LAS VENTAJAS DE LA INCOMPRENSIÓN
}

\author{
THE FATAL KAFKA AND THE ADVANTAGES OF THE INCOMPREHENSION **
}

\section{Alí Víquez Jiménez*}

\section{RESUMEN}

Por medio principalmente del examen de tres relatos, "El artista del trapecio", "El artista del hambre" y "Josefina la cantora o el pueblo de los ratones", este ensayo elabora una estética kafkiana en la que el arte como ejecución de un ars moriendi y el proceso de recepción como "malentendido provechoso" se destacan. Palabras clave: Literatura checa, narrativa europea, relato corto, Kafka, estética kafkiana.

\begin{abstract}
Basically by analyzing three short stories: "The Trapeze Artist", "The Hunger Artist" and "Josephine the Singer or the Mouse Folk", this essay elaborates a Kafkaesque aesthetic in which, it is highlighted the art as the performance of a ars moriendi and the reception process as "Advantageous Misunderstanding".

Key Words: Czech literature, European narration, short story, Kafka, Kafkaesque aesthetic.
\end{abstract}

* Profesor, Escuela de Filología, Lingüística y Literatura. Universidad de Costa Rica.

** Traducción: Lic. Geannette Soto. Escuela de Lenguas Modernas, Universidad de Costa Rica.

Correo electrónico: aviquez@yahoo.com

Recepción: 14/07/11. Aceptación: 03/06/13. 


\section{Introducción}

Entre las muchas deudas que tenemos con Franz Kafka, una de las mayores parece ser Cien años de soledad. Al decir de García Márquez (1993: 41), su vocación literaria se vio definitivamente asegurada cuando de muchacho leyó que “...al despertar una mañana, tras un sueño intranquilo, Gregorio Samsa se encontró en su cama convertido en un insecto". Entonces, se dijo que si la literatura permitía hacer eso, a él por cierto le interesaba hacer literatura. Y el resto es historia...

En este ensayo, quiero elaborar una reflexión sobre la estética kafkiana. Precursor de tantas posibilidades dentro de lo literario que algunos le atribuyen el ser (con Proust y Joyce) uno de los pilares de la literatura del siglo XX, también lo ha sido Kafka en cuanto a incluir en su obra la reflexión no sólo sobre el ser humano y su mundo y su Dios o la ausencia de su Dios, sino también sobre el arte y la literatura mismos. Sin que esto quiera decir que Kafka sea rigurosamente el primero en ostentar en su producción este rasgo. Todo arte mayor, desde siempre, ha tenido una palabra que decir acerca de sí mismo. Pero Kafka inaugura un periodo de acentuación en este sentido que ha sido característico a partir del siglo XX.

Kafka se lanza pues por un camino que habrán de seguir no pocos artistas posteriores: la creación de una obra que se piensa a sí misma, que no sólo ejecuta el arte, sino que se pregunta sobre las pretensiones, posibilidades y realizaciones de este. A partir de Kafka, ya no será raro que la literatura se tenga por objeto de trabajo, ni que se detenga ahí, minuciosamente, en un movimiento que alguien ha calificado como "narcisista", pero que es de justicia calificar mejor como de "autoconciencia". (Y es que la autoconciencia puede producir narcisismo, lo que estaría expresado maravillosamente en Oscar Wilde: cuando Dorian Gray hace del retrato el portador de su realidad personal profunda (vale decir, casi exclusivamente de su maldad), el acto se traduce en una aceptación del peso del objeto de arte como portador de la verdad, tanto como en una simultánea contemplación del retrato por parte del propio Dorian Gray, es decir, una contemplación narcisista. La diferencia, como bien nos hace ver Rafael Ángel Herra, es que Narciso se ama, mientras Dorian Gray se odia, pero ambos se autocontemplan ${ }^{1}$ ). Este ensayo quiere expresar lo que puede deducirse sobre las nociones de arte en la obra de un autor que ha sido capaz de ampliar los horizontes estéticos hasta un punto sumamente inspirador, no sólo para García Márquez, pero afortunadamente también para este. ¿Qué pensaba sobre arte aquel que ha sido uno de los pocos capaces de llevarlo más allá de donde se lo había llevado antes?

Aquí voy a centrar mi atención en tres relatos cortos: "Un artista del trapecio", "Un artista del hambre" y "Josefina la cantora o el pueblo de los ratones". Podrían incluirse más textos kafkianos en los que se encuentra material relacionado con la reflexión estética y, de hecho, cuando sea el caso recurriré tangencialmente a otras fuentes, pero creo que en estas tres se encuentra el grueso del tema desarrollado por Kafka. Quizá llame la atención el que no se menciona dentro del corpus principal las grandes novelas kafkianas (El Proceso, El Castillo y América $^{2}$ ), ni el relato más famoso, incluso ya citado al principio, "La metamorfosis". Las razones para esta omisión tienen que ver con que este ensayo forma parte de una investigación mayor que pretende dilucidar el fundamento filosófico del proceso con que se enjuicia a Dios (esto condujo ya a un primer artículo, dedicado a El proceso y a la comparación con el juicio similar que ejecuta el personaje dostoievskiano de Iván Karamázov) y la descripción de la conducta y la suerte humanas en un mundo de exclusiones sistemáticas (lo que conducirá, espero, a un tercer artículo centrado en $\mathrm{El}$ Castillo, "La metamorfosis" y algunos de los aforismos kafkianos). En medio de ellos, este ensayo quiere responder a las preguntas que por el arte se hizo un artista como Kafka, tras enjuiciar a Dios y a la luz del desamparo humano. Si se quiere, puedo describir mi movimiento escritural del modo siguiente: me he preguntado adónde conduce en una obra de arte la culpa (en primer lugar, la de Dios, si lo que escribí en el primer ensayo es válido) y, antes de 
detenerme en los detalles de una vida en total desamparo resultante de ese ocultamiento de la trascendencia (como los que veré al dedicarme a los pormenores del peregrinar de K. en su afán de penetrar en el imposible castillo o de la tragedia de Gregorio Samsa cuando se lo excluye de la raza humana), quiero visualizar las posibilidades que el instrumento elegido para ejecutar el estudio, la obra de arte, pretende ostentar, de acuerdo con lo que el propio artista ejecutante ha propuesto. He reservado, así, ciertos textos para que me hablen de los propósitos filosóficos mayores de la obra kafkiana (sus tres novelas, su relato más famoso, sus aforismos ${ }^{3}$ ), $y$ he querido usar ciertos relatos breves para que me hablen de la forma en que efectúan la reflexión meta-artística, constante acaso en toda la obra de Kafka, pero especialmente poderosa - si no me equivoco-en los tres relatos elegidos. He repartido, pues, los temas entre los textos, aunque mejor diré que lo he hecho "sobre los textos", por lo cual me permitiré también eventuales traslapes.

\section{Un artista del trapecio}

El artista del trapecio ${ }^{4}$ representa un caso de artista plenamente reconocido por el público y apreciado por sus méritos. La misma posición que ocupa lo confirma literal y simbólicamente: vive en lo alto de las cúpulas de grandes circos, allí donde los demás se asoman sin poder llegar. Se señala incluso, como una molestia generada por el hiperbólico hecho de que jamás el artista abandona las alturas, el que durante los otros actos del circo no pueden evitarse las miradas del curioso público hacia donde él se encuentra, lo que implica la generación de distracciones. Pero no debe pasársenos que el hacerlo ver aquí como un "distractor" también implica el valorarlo positivamente: quiere decir que el artista del trapecio no puede dejar de despertar interés, incluso cuando no es el caso que lo haga y cuando él mismo no lo pretende.

Entonces, por un lado, la hipérbole citada tiene implicaciones en cuanto a la dedicación necesaria del artista. El artista del trapecio decide literalmente vivir sin abandonar el trapecio nunca por la necesidad de perfeccionamiento en relación con un arte extremadamente difícil. $\mathrm{El}$ arte exige de sus productores compromiso total; no se nos pase por alto que Kafka vivió, según lo comprueban su diario y sobre todo su correspondencia con mujeres a las que estuvo ligado sentimentalmente, siempre agobiado porque no creía compatibles su deseo de escribir y la vida matrimonial que también, en apariencia, deseaba, pero no con la misma intensidad o al menos no con la misma regularidad ${ }^{5}$. Kafka sólo creía en el ejercicio de un arte tiránico, absorbente en un ciento por ciento, pero que asimismo era el ideal del verdadero artista que él aspiraba a ser: su meta era llegar a confundir su "ser" con el "ser artista". Una dictadura que contaba con el beneplácito de su víctima: la existencia que Kafka llegó a entrever como ideal de vida implicaba la renuncia a todo aquello que no estuviera directamente ligado con el arte (de aquí sus numerosas quejas en torno al trabajo de oficina que se veía obligado a desempeñar para ganarse el pan, lamento que no tomaba en cuenta el hecho de que Kafka sacaba de su interacción con el entorno no pocos conocimientos que luego vertía en su obra: imposible concebir a un Franz Kakfa que no hubiese presenciado los vericuetos interminables de las burocracias). Por eso, al menos al principio de su vida adulta, su intención de formar una familia suena más a una suerte de intención de cumplir que a una verdadera decisión acerca de lo que quería hacer $^{6}$. La carta a Felice Bauer del 15 de enero de 1913 debió de resultar chocante a su destinataria, quien -después de todo-aspiraba a un futuro en común con el atolondrado y sincero emisor ${ }^{7}$ :

Un jour tu as écrit que tu voudrais être assise auprès de moi, tandis que j'écrirais; mais penses-y donc, alors je ne pourrais plus écrire (autrement, déjà, je ne le puis guère), mais alors je ne le pourrais plus du tout. Écrire signifie s'ouvrir jusqu'à la démesure; l'extrême ouverture où un être croit déjà se perdre dans les rapports humains et devant laquelle, toujours, s'il est de raison, il cherchera à se retirer, effarouché, --car chacun veut vivre aussi longtemps qu'il vit-, cette ouverture et ce don du coeur ne suffisent pas, et de loin, à l'écriture -à moins qu'il n'en aille autrement et que les 
profondes sources ne se taisent-n'est rien et s'effondre, à l'instant où un vrai sentiment vient à ébranler ce sol situé au-dessus. C'est pourquoi, on ne saurait être assez seul, quand on écrit; c'est pourquoi, jamais assez de silence autour de soi, quand on écrit; la nuit est encore trop peu la nuit... Souvent j'ai pensé quepour moi la meilleure manière de vivre serait de m'établir, avec mon matériel d'écriture et une lampe, dans l'espace le plus intérieur d'une cave étendue et fermée. On m'apporterait de quoi manger, mais toujours loin de l'endroit où je me tiendrais, derrière la porte la plus extérieure de la cave. Mon unique promenade serait d'aller chercher, en robe de chambre, cette nourriture en passant sous toutes les voûtes de la cave. Puis je reviendrais à la table, je mangerais lentement et avec componction, et tout aussi-tôt je recommencerais à écrire. (Blanchot, 1981: 226).

Por otro lado, la hipérbole implica un ocultamiento o al menos la minimización de las necesidades de la vida práctica: todo lo que el artista puede precisar como parte de esta se atribuye vagamente al trabajo de criados que suben y bajan cestillos con aquello de que dispone o que desecha el artista de arriba. La visión que se construye del artista disimula pues todas las verdades malolientes de la existencia del cuerpo, como si el artista, por su vocación y su trabajo, consiguiera convertirse en un ser poco menos que etéreo: sus exigencias materiales se describen como "muy pequeñas" y son rápidamente cubiertas, sin molestia destacable.

No sólo este hasta cierto punto etéreo artista resulta apreciado por el público, también lo califican de "extraordinario" e "insustituible" los directores del circo, es decir, la jerarquía institucional en cuyo marco existen su arte y su vida. Está claro que el artista del trapecio depende de estos para realizarse como ser humano (lo que, dado que es artista, equivale a realizarse en su arte); tiene la suerte de que ellos no sólo lo ayudan a hacerlo, sino que además manifiestan un conocimiento profundo de las necesidades espirituales y técnicas del artista, pues no ignoran que la "extrema perfección de su arte" requiere esfuerzos como los que el trapecista efectúa, y ellos le proporcionan las herramientas prácticas para tal. Parecería que el artista no ha podido caer en mejores manos, manos incluso no poco paternales, si bien dentro de un marco en el que se saca provecho económico de él. (Por lo demás, está claro, desde un principio, que el artista del trapecio vive en un circo, y que este lo dirigen empresarios por supuesto interesados en la rentabilidad de las actividades circenses. La bondad de los empresarios no debe entenderse como sinónimo de un sacrificio por el arte o una suerte de apreciación del arte por el arte. El estado en que se encuentra el trapecista es el mejor de los posibles, pero dentro del mundo real. Pasajes como este hacen de Kafka no un escritor fantasioso; todo lo contrario, es un escritor de literatura fantástica sumamente realista.)

Pero el destino del artista es la insatisfacción. Incluso este trapecista, admirado y querido por su entorno (el público $\mathrm{y}$ sus directores), y que representa una suerte de ideal inalcanzable de vida desligada de las preocupaciones cotidianas y dedicada al arte, allá en las alturas, conoce -en forma creciente, según parece anunciar el final del relato-la desesperación. Esta se genera dentro del arte mismo: un día, no puede evitarse el romper en lágrimas al pensar que trabaja con un solo trapecio, cuando debería tener dos.

La inmanencia estética del problema se torna evidente. Esta, en primer lugar, se anunció desde el momento en que al trapecista se le ha llamado más a menudo "artista del trapecio" 8 ". Ahora, se nos advierte que un problema surgido de la inquietud personal del artista es lo que a este le preocupa, y no porque el empresario o director haya sugerido que deba mejorarse el acto o porque el público haya perdido algún interés (de hecho, el trapecista se halla -literal y simbólicamente, de nuevo-en la cúspide de su fama). Su arte es pura performance, pura ejecución efímera incapaz de la perduración, "pura pureza", si se quiere: dato significativo es que no aspira el relato a describir las ejecuciones del trapecista, tan sólo a dar cuenta de la admiración que suscitan; su acto es como esa música sublime al que cualquier comentario le queda muy corto. El trapecio es un espacio abierto y lleno sólo en la medida en que se produzca la magia estética del trapecista ante las miradas deslumbradas de su público; su cuerpo es entonces el productor de un arte que 
lo atraviesa en la altura pero que no se queda en ese cuerpo, tal como se ha dicho que la poesía atraviesa al poema sin confundirse con él. Dos trapecios en lugar de uno representan la necesidad de una evolución en ese encuentro del cuerpo del trapecista con un arte que exige nuevas técnicas, así como el escritor lucha con el lenguaje del poema para conseguir el toque mágico de la poesía, que sin embargo no se encuentra en alguna palabra en particular ni en todas ellas en su conjunto: el arte se da por una plusvalía misteriosa que adquieren los elementos concretos con que se lo construye.

Al cobrar conciencia de una limitación técnica (amarga conciencia, inconsolable durante el largo rato en que el empresario se esfuerza por calmar al artista), lo que en el fondo se yergue como amenaza es la eventual pérdida de la habilidad para conseguir la elevación estética (aquí, una vez más, literal y simbólica). Y es que el arte no puede basarse en la actuación pasada, que ya no existe (así se haya escrito en piedra un libro, mucho más si todo lo que se ha hecho sólo ha quedado grabado en las retinas del público que, aunque admirado, también es olvidadizo ${ }^{9}$ ), el arte tiene sus miras siempre en la posibilidad futura. Lo pasado no vale por la sencilla razón de que ha pasado; la renovación no sólo es conveniente, es indispensable. De aquí el horror del artista al pensar que alguna vez, en el futuro, pueda verse obligado a volver a actuar con un único trapecio: ello equivaldría a tener que repetirse, sin posibilidad de éxito, porque el arte puede ocurrir una sola vez. Con esto quiero decir que la obra de arte, el objeto, puede permanecer, pero ello no tiene importancia estética verdadera: es la sensación estética la que importa, y esta sólo puede darse en un caso particular; para reintentarla, hay necesariamente que vivirla de un modo diferente. (Un momento no se puede vivir intensamente dos veces; la segunda implica, si la vivencia es genuinamente estética, un cambio respecto de la primera. Nadie baja dos veces al mismo río "de la poesía”, deberá agregarse; quizá sí se pueda bajar dos veces al mismo río del aburrimiento.) Creo que el visualizar la "pura pureza" del acto del trapecista ayuda a entender lo que trato de decir: este acto será distinto en cada ocasión que se realice y es esto lo que en el fondo implica la exigencia de los dos trapecios. El libro ya escrito no salva al escritor, para quien es ya un león muerto (el decir de Hemingway que García Márquez cita al justificar el por qué él no vuelve a leer los libros que ha publicado ya); sólo el libro que está en el horizonte ofrece alguna esperanza de llegar allí donde se quiere.

Ese lugar-Kafka lo sabe-es imposible. Dos trapecios no serán suficientes: es simplemente algo que está más alto, una belleza que no se codea con piruetas concretas y, en el fondo, despreciables. Como el asco que siente el poeta cuando mira hacia la pobreza de sus palabras, por hermosas que le hayan parecido al momento de enunciarlas: después comprobará, si la vanidad del aplauso no lo enceguece, que son sólo dos miserables trapecios. Y si el público y el empresario apreciarán el doble lo que apreciaban con un solo trapecio, sólo hay una cosa por agregar: el público y el empresario no saben nada. (Este incluso se atreve a decir que los nuevos trapecios serán "más variados y vistosos", como si el arte se dejara tocar por objetos de semejante calaña, al modo -agrego yo-de esas gentes que profieren alabanzas a los poemas basados en sus deplorables méritos externos, como la perfección formal que ostentan o, peor aún y más frecuente, los premios literarios que le han sido concedidos al autor: vanidad de vanidades.) La sensibilidad profunda del artista es la única capaz de juzgar verdaderamente los alcances de su arte, y aunque, de momento, hacia el final del relato, el trapecista descansa, tranquilizado por la promesa del segundo trapecio que viene, ello sólo es producto del cansancio. Las horas de mucho trabajo le retribuyen la tranquilidad física; esa fatiga es una de las pocas recompensas que obtiene, pero no una satisfacción espiritual confiable, perdurable. Curiosamente, y sin entender las causas reales de la tragedia del artista, el empresario es quien anticipa, antes que el propio trapecista, que el sufrimiento y el dolor se han hecho inevitables: "Si semejantes pensamientos habían empezado a atormentarle, ¿podrían ya cesar por completo? ¿No seguirían aumentando día por día? ¿No amenazarían su 
existencia? Y el empresario, alarmado, creyó ver en aquel sueño, aparentemente tranquilo, en que habían terminado los lloros, comenzar a dibujarse la primera arruga en la lisa frente infantil del artista del trapecio." (Kafka, 1985: 43). Es un ojo externo el que, sin capturar los motivos, sabe capturar las consecuencias: en adelante, nada será suficiente para que el artista se sienta bien. Los que miran el arte sin producirlo, los espectadores que se hallan fuera, pueden testimoniar la tragedia del artista aunque no conozcan sus causas profundas: hay que haberse embarcado en la exigencia del arte, no como negocio o pasatiempo, sino como alimento vital, esencial, para comprender el por qué de la insatisfacción, la experiencia de una belleza siempre huidiza y atormentadora. Las alabanzas del público y la actitud paternal del empresario no pueden remediar que el artista está finalmente solo ante su obra y que la juzgue torpe, dañina incluso ${ }^{10}$, del mismo modo que está solo ante su vida y la sabe desgraciada. Casi está de más recordar que si alguien ha habido lleno de dudas acerca de su valía como artista, si alguien se ha creído en amargos momentos (largos momentos, frecuentes momentos, casi permanentes) sólo un patético trapecista que con dos aparatejos esperaba llegar hasta las verdaderas alturas de la belleza, ese ha sido Franz Kafka. Al final, pedirle a Brod la quema de los libros es la demostración más palpable de que no se tiene confianza íntima en las propias piruetas. La opinión de los demás, dada esta carencia fundamental, viene a ser deleznable.

\section{Un artista del hambre}

Bueno, casi cualquier padre de familia al que su descendencia le haya anunciado la intención de ser artista ha reaccionado con las mismas palabras de escándalo: "Te vas a morir de hambre". Mezcla de amenaza infundada (¿acaso no hay artistas exitosos desde el punto de vista económico?, ¿acaso no los ha habido siempre?) con realismo de estadística (¿acaso no ocurre que la mayoría de los artistas padecen carencias materiales?, ¿acaso no es verdad que casi todos se ven en la necesidad de recurrir a otros oficios para financiarse su ruinoso quehacer artístico?), el padre advierte al hijo por su propio bien. No le desea el fracaso, pero le hace ver las dificultades enormes que el camino elegido tiene en el mundo real, el único en el que se puede vivir, y en donde el dinero cuenta y cuenta. ¿O quizás, secretamente, sí le desea el fracaso, porque no tolera ver en el hijo a un escapista de las responsabilidades que él, como buen padre proveedor, no ha podido eludir, cual fue tal vez también su deseo? ¿Es de repugnancia ante la libertad del hijo que se tiñe la amenaza, menos que de genuina preocupación protectora? Al elegir el camino del arte, renuncia el hijo a una seguridad económica que otra ocupación pudiera procurarle, e implícitamente renuncia a ser un fiel reflejo del padre, pues ya no será como este, ya no dedicará todos sus esfuerzos a ser el confiable aunque a ratos agobiado pater familiae que ha sido su propio progenitor. La cadena se rompe; el rol que generaciones han heredado se resquebraja por la culpa de este hijo que se ha dejado tentar por la libertad y por una vocación inútil, ociosa, viciosa incluso. El padre entiende muy poco de arte, pero sabe lo suficiente como para emitir el juicio de que, dado que no produce buen dinero, tampoco ha de ser muy importante. El padre, cuando se ha asomado a eso que el hijo genera, lo ha encontrado bastante incomprensible. Por otra parte, tampoco le ha gustado el entorno en el que la actividad se da: demasiada relajación, por no decir "relajo", y muy poco sentido del deber.

$\mathrm{Y}$ sin embargo el hijo se pasa la vida escribiendo tanto ese arte como afirmando en su diario, en sus cartas y quién sabe dónde más, que su objetivo en la vida es llegar a ser él mismo un padre de familia. Para muestra un botón, extraído de un rosal lleno de espinas minuciosamente dispuestas para herir al destinatario, la Carta al padre: "Casarse, fundar una familia, aceptar todos los hijos que vengan, mantenerlos en este mundo tan inseguro e incluso guiarlos un poco, es lo máximo que, según mi convicción, puede conseguir un hombre." (Kafka, 1984: $54)^{11}$. No quiere el hijo dejar su arte, pero espera que un milagro, un gran golpe de suerte, una 
situación excepcional que él pueda alentar o que simplemente se le dé, le permita cumplir su deseo de unir vocación artística con paternidad. Al fin y al cabo, los precedentes existen; tampoco está pegado del cielo que un artista (quien, por lo demás, cuenta con un oficio diurno como burócrata de cierta importancia) pueda mantener a una familia. Es, por cierto, exagerado que a los artistas los aniquile la inanición; algunos casos se han dado, pero la mayoría de las veces la expresión "morirse de hambre" es hiperbólica.

Salvo, claro, que el arte por desarrollar sea el de pasar hambres ${ }^{12}$. Entonces todos los buenos temores o todos los peores deseos de venganza del padre se habrán de cumplir devastadoramente. Más aún si sumamos la desafortunada circunstancia de que el arte del ayuno ha dejado de ser relevante (es lo primero de que nos enteramos: "En los últimos decenios, el interés por los ayunadores ha decaído muchísimo."): si ni siquiera un ayunador apreciado puede dejar de pasar hambres, ¿qué lamentable destino le espera a un ayunador no apreciado? Este texto nos pinta esa suerte, con ese tono de aceptación pausada ante lo inexorable tan característico de Kafka.

$\mathrm{Si}$ el relato comentado inmediatamente antes nos hacía ver una serie de problemas dados en la pureza estética de una vivencia socialmente exitosa del arte (y ese éxito le aseguraba al trapecista la soledad necesaria para dedicarse a su labor, tanto como los medios, provistos por su entorno, que resguardaban su aislamiento), este otro texto parte de lo contrario: el entorno es casi enteramente hostil. Y no se nos esconde la dependencia directa del ejercicio del arte hacia su entorno: los ayunadores son vistos, sin más, como un negocio cuya exhibición antaño era muy rentable y hoy ha dejado de serlo. En esta medida, en el mundo real (el mundo material, en el que los padres traen a vivir a los hijos), la historia del ayunador es una historia destinada a conocer el final definitivo de un ejercicio artístico. Este no podrá existir sin el soporte económico que ahora ha llegado a su fin.

$\mathrm{Ni}$ siquiera el hambre deja de provocar gastos: tal paradoja sólo ha podido provenir de la pluma mordaz de un Franz Kafka. Estamos en una de esas situaciones que en principio causan risa (Deleuze y Guattari aseguran que las lecturas que ante amigos hizo Kafka de pasajes de El proceso despertaban la hilaridad de la concurrencia), pero que, después de un poco de reflexión, nos dejan con pesar (¿quién conseguirá hoy reírse con la oscura suerte de Josef K., sino un verdadero cínico?). La situación es quijotesca: la risa y la tristeza se superponen. Una alusión directa a don Quijote no debe dejar de comentarse: Kafka escribió, en "La verdad sobre Sancho Panza" (Kafka, 1983: 80) que Sancho, autor de novelas de caballería, aleja de sí a su demonio dándole el nombre de don Quijote, pero luego no permite que este se vaya solo: lo sigue, con lo cual también consigue cierto esparcimiento. El arte produce un exorcismo, pero no total: Sancho (el texto aclara: "hombre libre") saca de sí a don Quijote pero luego se ve en la obligación, por "cierto sentido de la responsabilidad", de ir tras él. El esparcimiento que encontrará al seguirlo lo compensará por la limitación de su libertad al ir tras su demonio, el desempeño del rol de criado ante el amo don Quijote. La esclavitud y la libertad también se superponen.

A diferencia de Sancho, el artista del hambre no ha elegido libremente su vocación, pues, según confiesa al final, le es forzoso ayunar. Pero, ¿realmente Sancho es libre de comenzar a escribir los libros de caballerías? ¿O más bien se convierte en hombre libre una vez que los ha escrito, y ha conjurado con ello a su demonio? En todo caso, ya hemos visto que inmediatamente ocurre una limitación en la libertad de Sancho, y así se convierte en criado de su demonio Quijote. De manera que puede sospecharse que en el fondo para Sancho ha sido forzoso escribir antes, y ahora lo es el seguir a don Quijote. El artista no puede desentenderse de la responsabilidad que le cabe por ser un creador; tampoco el artista del hambre evita la responsabilidad de ser honesto: no tolera que lo admiren, pues sabe que su hambre se le ha impuesto como una obligación, ya que ninguna comida le ha gustado. Ese es su gran secreto, no revelado hasta el final del relato, cuando ya su ejercicio artístico está por clausurarse. Por eso no 
debe admirársele, y su honestidad no admite ni siquiera este pequeño triunfo falaz (más pequeño si pensamos que esa dudosa admiración no le granjea mayor apoyo por parte de las personas). Lo que el padre debería saber ante el hijo artista es que, si este pudiera comer lo mismo que él come y hacerlo con gusto, inmediatamente lo haría. La suya no ha sido en el fondo una libre elección, como acaso ha pensado el padre lleno de enojo: ha sido una imposición del destino. Verdad que se convierte de Perogrullo, gracias a la maestría del planteamiento kafkiano: nadie elige pasar hambres. La vocación por el arte es desdichada e ineluctable.

Las hostilidades a las que se ve enfrentado el artista del hambre, al principio, tienen que ver con la desconfianza en su honradez. Los vigilantes a su alrededor viven convencidos de que ni siquiera con su minuciosa y despiadada actividad policiaca evitan la ingestión fraudulenta de alimentos por parte del ayunador. Está claro que hay un divorcio fundamental entre el artista y su público, pues este último participa de dudas similares: nadie puede creer que el ayunador llegue a los extremos a los que efectivamente llega. Se trata de un problema de verosimilitud, no de verdad: no se está dispuesto a aceptar que sea posible extender un ayuno más allá de cierto plazo; por lo tanto, la colectividad impone un criterio al cual la realidad le importa poco. Se trata, por lo demás, de un asunto de capacidades: simplemente, el público (y en primer lugar los vigilantes, que son carniceros) no está preparado para creer en la intensidad de un deseo de ayunar como el que tiene este artista, el cual lo lleva a extremos que, a falta de creyentes que no sean él mismo, nadie da por válidos. Ni siquiera es mala fe, lo que al menos habría provisto al artista del consuelo de saberse perseguido: la gente no le cree porque no puede.

Por ello, el arte, en el fondo, se ejecuta sólo para el artista mismo, quien es el único capaz de creer en su propia honradez: los demás siempre habrán de pensar en migajas ingeridas subrepticiamente o en cuentas mal llevadas o amañadas por el empresario. Quienquiera que mira al artista desde fuera de su jaula (de nuevo, literal y simbólicamente) es incapaz de saber lo que verdaderamente ocurre en su interior. La jaula es completamente real como objeto de encierrro; el circo la provee y la vigila, el cuerpo del artista no la puede abandonar, la cárcel de la institución no tiene nada de meramente imaginaria y es rotunda; dicho esto en forma tajante, aceptemos que la jaula más importante es la que el propio artista se procura dado su compromiso espiritual con su arte. El compromiso espiritual del artista se da en su trato con el cuerpo al que somete a ayunos: el arte es un asunto de cuerpo y alma. La tragedia del artista consiste en ser el único a quien consta cuál es su íntimo compromiso con el trabajo, pero no conseguir aislarse puesto que la actividad que desarrolla depende de un lugar en el circo: sin este, que representa a la institución, el artista tampoco logra existir. Esta tragedia es también su paradoja: ayuna para exhibirse, porque de lo contrario no conseguiría tener condiciones para ayunar; pero parte del modesto éxito de la exhibición está basada en provocar la sospecha acerca del inexistente fraude. Como esos números de feria en que se nos anuncia la exhibición de una mujer que se transformará en simio ante nuestros ojos: la entrada se paga no para creer en la metamorfosis, sino para sonreír ante lo burdo de un engaño al que sólo los niños pequeños serán susceptibles. Así, el artista del hambre aspira a un desempeño elevado y sólo consigue una estimación en términos de número de burlas en la feria, lo cual finalmente se expresa en la colocación que se hace de su jaula: una suerte de estorbo en el camino hacia las cuadras de los animales, que son el verdadero centro de atención.

Así que si, como vimos en el relato del artista del trapecio, la comprensión del público no puede salvar al artista de la insatisfacción y la desdicha, resulta que la falta de ella agrava las cosas. Pues de esta incomprensión nace el hecho de que el artista del hambre es forzado a acabar con su ayuno cada cuarenta días, y esto por cuanto, luego de ese tiempo, su número no despierta siquiera escaso interés ${ }^{13}$. El empresario lo obliga a detenerse, todo como parte del espectáculo, pues las personas asisten a ver el término del ayuno como la culminación 
real del acto. Pero él, “...ni una sola vez, al fin de su ayuno -esta justicia habría que hacérsela-, había abandonado su jaula voluntariamente." (Kafka, 1985: 23). Si el artista compartiera la opinión de que el abandono de la jaula y la ingesta de alimentos culminan su exhibición, no se resistiría a ello. Pero los demás, como no lo entienden, le cercenan su posibilidad de seguir indefinidamente: hay que decir que la interminable novela kafkiana (todas ellas, pero sobre todo El castillo, que, a diferencia de $E l$ proceso, no incluye un capítulo con la muerte del protagonista) se puede parecer mucho a esto cuando se enfrenta a lectores que exigen un final definitivo ${ }^{14}$. A estos lectores, deberá recordárseles que el hambre sólo puede continuar indefinidamente cuando se le ejecuta por un compromiso espiritual, y este compromiso va más allá de la tolerancia habitual del público lector. La novela kafkiana que jamás se publicó en vida del autor (es decir, toda ella) no podía ceder voluntariamente a la exigencia de un empresario circense que hubiera impuesto un final, no podía descender a la vulgar exhibición de la feria pueblerina de bajar el telón y recibir aplausos, pues en este caso lo que se sacrifica es el hambre mismo, que debe continuarse como en este relato: hasta la muerte. En el tránsito final, pedirle a Brod quemar los manuscritos es pedirle que preserve el hambre secreta que es el arte; la decisión de Brod de publicar (e incluso armar un poco los textos para dar, sobre todo en $E l$ proceso, la impresión de un cierre) es la decisión de convertirse en el empresario que sabe que por encima de todo el espectáculo debe continuar, y para ello hay que complacer al público. No lo condeno por ello; ni siquiera lo critico: el empresario es indispensable en el mundo real para que el arte llegue a nosotros, pero no por eso hay que obviar que Brod -digamos que lleno de buenas intenciones que deben aplaudirseno capturó la esencia de la petición final de Kafka. Permítaseme la paradoja: qué bueno que no lo hizo; en este caso, la incomprensión ha posibilitado la difusión y ha resultado ventajosa. $\mathrm{Y}$ volvamos sobre Kafka, que interesa mucho más que Brod el empresario. Entiéndase que no fue por creer indignas de los lectores que Kafka pretende silenciar sus obras; es al contrario: porque cree que los lectores no lograrán ponerse a la altura de sus obras, porque los sabe (o nos sabe, aceptémoslo de una buena vez) irremediablemente poco preparados para comprender la verdad espiritual que se expresa en el hecho escandaloso y cierto de que el arte se nutre del hambre y por eso el verdadero artista no come ${ }^{15}$.

Pues así es: el arte se sustenta del hambre. Es más, en este caso Kafka ha logrado ir más allá: el arte se confunde con el hambre, el arte es hambre. Ya las preocupaciones (fundamentadas, por cierto) de si el arte puede dar de comer o no pasan muy al segundo plano. Lo que vale es que el arte es un hambre en lo que tiene de más importante, pues el hambre, aunque pase por el cuerpo, es espiritual. O más bien habría que aclarar: en el arte más genuino, el cuerpo es el alma. Este no es un planteamiento de corte completamente idealista, porque no se trata de sostener que el arte actúa en el ser humano convirtiéndolo sólo en un espíritu etéreo, aunque esa quizá sea su intención más de fondo. Más bien, se sostiene que el arte actúa en la raíz del cuerpo, en lo que tiene de más elemental, en su apetito, en su deseo de comer. Y es ahí, en su origen material, y quedándose ahí, donde sin embargo se da un salto cualitativo para hacer de la vida material del hombre una obra de arte. La forma de hacer esto, que suena incluso contradictorio, es precisamente no cediendo a la satisfacción del deseo; el artista permanece indefinidamente en el ayuno, que así lo nutre.

Cuentan (en mi memoria se ha perdido la fuente, y mucho menos sé si esto es verdad, pero ya se verá que no importa) que Salvador Dalí salía por las calles de Nueva York en procura de una mujer que llevar a su apartamento. (Gala, en principio, lo permitía; ya se verá por qué.) Como su excentricidad no era rápidamente apreciada por el elemento femenino de la ciudad, aquella cacería podía extenderse por horas, probablemente muchas, y el apetito (no el sexual, el otro) del pintor errante se acrecentaba. Pero no cejaba en sus empeños hasta tener éxito. Llegados al interior de la morada, Dalí le indicaba a la mujer que se despojara de su ropa, 
freía un huevo y lo depositaba sobre la frente de su maja desnuda. Luego le decía: "Ni te toco, ni me como el huevo, porque lo que me gusta es el deseo."

Permítaseme afirmar que el arte es un ejercicio de insatisfacción perpetua. A este ejercicio, lo hemos visto ya, se ve forzado el artista. Si supiera cómo satisfacerse, lo haría. Para no meterme con la vida personal y privada de Salvador Dalí, nada diré acerca de él y las mujeres, voy a atreverme sólo a deducir que los huevos no serían una comida extremadamente tentadora para él: de haber sido así, no los hubiera resistido. Adivinamos, además, que eventualmente comió eso u otra cosa. (La empresaria y musa Gala solía traer a colación el gusto de Dalí por los filetes, a la hora de justificar las recolectas de los inexorables pagos por el trabajo pictórico de su marido. No la critico, pues le asistía la razón; el punto es que no yo no me trago que estos filetes se hayan quedado huérfanos de diente andaluz.) Recordemos que el secreto del artista del hambre es que ninguna comida le gustaba.

Así es, en efecto. Cualquier cosa con la que se sacia el deseo de un artista, llamémosla su obra, resulta un mero paliativo a su insatisfacción esencial. Una curación provisional, un mero dispositivo para consolación momentánea. Nuestro ayunador era probablemente el mayor ayunador de todos los tiempos, como dice el texto (y aquí tomémonos la libertad de leer "el mayor artista de todos los tiempos"), por una razón inapelable: siendo artista del hambre, había conseguido la pureza de un arte que confundía el deseo con la producción artística. El objetivo a que aspira todo artista y jamás consigue.

Puede el artista ayunar de su comida, pero no de las consecuencias de su actividad. El ayunador evidentemente se dirige, en razón de su arte mismo, hacia la muerte. Por supuesto que contra esto se puede argüir demoladoramente lo siguiente: ¿y quién no se dirige hacia la muerte? La particularidad del artista es que el arte que practica es una inducción directa a la muerte. Para quienes (y algunos artistas se cuentan entre estos, posiblemente sea el caso de Josefina la cantora, de la que hablaré pronto) creen que el arte se ejecuta para eludir a la muerte, para eternizarse de una manera simbólica con creaciones que perdurarán en el tiempo, Kafka es un trago amargo, pues enseña que el arte más bien es una actividad de inducción a la muerte, y el artista es alguien que ha decidido dedicarse a algo que lo matará más temprano que tarde. Este es el más grande de los artistas porque asume sin ambages la ejecución de un arte que es un irse matando a sí mismo: los demás artistas tardan años en ello, y siempre dando rodeos. Pero todo gran arte será a la larga un ars moriendi; el supremo objetivo del artista es morir ${ }^{16}$. Aceptación del destino humano, enamoramiento estético de este, vida en consecuencia como ejecución del arte en tanto producción de muerte. El estudiante de Salamanca, que va tras la Elvira macabra, enamorado de su calavera. Esto hace diferentes a los artistas, porque son aquellos a quienes no les ocurre simplemente el morir, sino que han hecho de su existencia un arte que los conduce a ello. Esto hace iguales a los artistas, porque al fin y al cabo morir es el destino de todos.

En la voraz pantera que ocupa la jaula que en vida fuera del artista del hambre, encontramos la insinuación final de que hay algo, una especie de libertad para la satisfacción desaforada del apetito, que a los humanos les fascina, pero que no tienen acceso a ello como lo tiene un animal salvaje. Pareciera que sólo quienes, como las bestias vencedoras en la naturaleza, consiguen alguna vez ignorar a la muerte, son capaces de vivir a plenitud. La pantera hechiza y produce miedo también; es violenta, vehículo de muerte ajena, y completamente abstraída de conciencia en torno a su propia mortalidad. No puede el arte de un hombre asemejársele: el ser humano se aproxima mucho más a un "ratón" miedoso, alguien que sabe que ha de morir, y cuyo arte sólo puede ser la consecuencia de esta certeza.

\section{Josefina la cantora o el pueblo de los ratones}

Las comillas en "ratón”, en el párrafo anterior, tienen una justificación. El ratón verdadero es una bestia tan abstraída de las 
preocupaciones estéticas o filosóficas como la pantera, pero aquí se trata de otra clase de ratón. Uno que puede ayudarnos a entrever, en su uso simbólico, una situación trágica que ahora comparten el artista y su pueblo. Los dos relatos anteriores parecieran insistir en el aislamiento del artista en relación con su entorno; sea que se lo aprecie o sea que no se lo haga, el artista vive tajantemente aislado del público, el cual no lo puede comprender en lo profundo de uno u otro modo: el éxito y el fracaso, esos dos impostores, sentencia Borges. Kafka probablemente diría que el éxito lo es más. En este relato, la situación no cambia, pero sí se le agrega una consideración: la de que el artista comparte un mismo destino con su pueblo, se le halla indisolublemente ligado a la colectividad no como un apéndice bien valorado (caso del artista del trapecio) o como un desechable desperdicio (caso del artista del hambre), sino como su representante más cabal, por encima de cualquier malentendido (y ya veremos que los hay siempre). Ya he dicho al finalizar el apartado anterior que el artista es diferente sin dejar de ser igual a los demás, y ahora se nos ahondará en este aspecto aparentemente contradictorio.

Véase que desde el título ya se apunta a una equivalencia, en un sentido que habrá de precisarse, entre la artista y su pueblo. De hecho, la voz narrativa se encuentra en este pueblo y ello queda asentado desde la primera frase: "Nuestra cantora se llama Josefina ${ }^{17 "}$ El tono laudatorio del principio del relato es mayúsculo: "Quien no la ha oído, no conoce el poder del canto." Aquí, como en "Un artista del trapecio", la consideración inicial versa sobre la apreciación (positiva o negativa) que el arte obtiene entre el público. Y si bien todo parece resultar beneficioso para la cantora Josefina en este inicio, los matices que vienen a complicar la situación no se hacen esperar. Las siguientes oraciones dicen: "No hay nadie a quien su canto no arrebate, prueba de su valor, ya que en general nuestra raza no aprecia la música. La quietud es nuestra música preferida..." A partir de aquí vendrán una serie de consideraciones que patentizarán la relación difícil de Josefina con un pueblo alejado de sus intenciones como artista, pero nunca indiferente ante estas. En realidad, el relato viene a ser la exposición de estas consideraciones, una prolongada indagación en los porqués de la clase de relación que tiene Josefina con el pueblo de los ratones. Como historia, aquí no pasa nada, sino que Josefina canta. O más bien, que Josefina es una ratona que canta para los demás ratones.

Pero debe reafirmarse el hecho de que la voz narrativa se encuentra en ese pueblo de "los demás ratones". Si en los otros relatos, la voz narrativa seguía a los artistas, aquí seguirá al público. Ya hemos visto que en Kafka los artistas son irremediablemente incomprendidos, desde la perspectiva de estos; ahora corresponde al público hablar de sus impresiones. Ese público, por cierto, de ser manifiestamente desafecto al artista, no tendría mucho qué preguntarse: le bastaría con asentir ante la aseveración de que no entiende ese quehacer. Así, en el caso del artista del hambre, la perspectiva del público carece de importancia: más allá de una pasajera curiosidad ante lo diferente, no hay nada elaborado sobre lo cual reflexionar, la comprensión simplemente no existe. (Recuérdese que hasta los que deseaban permanecer un rato ante la jaula del ayunador lo hacían más para fastidiar a los que traían prisa que por otra razón.) Pero un público que sí aprecia al artista es más complejo, pues aunque este se sepa incomprendido, sí se da alguna comprensión, posiblemente errónea, pero no ausente ${ }^{18}$. Esto se expresa aquí abiertamente: "Muchas veces me he preguntado qué ocurre realmente con esa música. Si somos totalmente amusicales, ¿cómo comprendemos el canto de Josefina o, más bien, ya que Josefina niega nuestra comprensión, creemos comprenderlo?” (Kafka, 2001:187-188) Nótese que el público es conciente de que el artista se considera incomprendido, y hasta está dispuesto a concederle razón. Por eso tendríamos que hablar de una paradójica "comprensión errónea ${ }^{19}$ ", en la cual quiere ahondar el relato.

"Para empezar, ¿es canto?", se interroga el narrador. Como se ve, la apreciación positiva expresada al principio no ha impedido que las dudas sobre la calidad de Josefina como cantora afloren, y de manera casi ofensiva. El decoro con que a la vista se cubre la relación con 
Josefina no puede sino saberse confundido con la hipocresía: "En círculos íntimos, no titubeamos en confesarnos que, como canto, el canto de Josefina no tiene nada de extraordinario." El punto es entonces que Josefina no es ni siquiera una cantora real, sino una emisora de un chillido ratonil que "...no sobrepasa los límites de un chillido común --hasta es posible que sus fuerzas ni siquiera alcancen para un chillido común, cuando un mero trabajador de la tierra puede chillar todo el día, mientras trabaja, sin cansarse..." (Kafka, 1988: 188). Pero el narrador no comete la simpleza de desautorizar a Josefina por esto (sí lo hace parcialmente, respecto a sus pretensiones), porque aún queda por esclarecer un hecho innegable y sorprendente: el efecto (más asombroso aún si pensamos que la supuesta cantora no canta en realidad) que producen los chillidos de Josefina.

La explicación se detalla, apegándose al texto, en cinco aspectos. El primero es que conviene, a todo aquel que quiera llamar la atención acerca de una acción cotidianamente ejecutada por cualquiera (en este caso, el chillido ratonil) el ser incluso un poco menos hábil que el promedio de los ejecutantes. De este modo, resaltará en su accionar lo que en otro pasaría inadvertido. Como una cierta torpeza al caminar puede hacer que veamos lo que no veríamos en el andar de una mujer. Josefina sabe producir un efecto a partir de un defecto, si bien ella, arrogante como es, jamás lo admitirá así. En esto interviene también su habilidad para sacar provecho de las siempre presentes contingencias adversas (ruidos, mala iluminación, problemas en reunir un público adecuado... al fin que se trata de una incómoda vida ratonil) y hacerlas ver como obstáculos que su arte vence, por lo cual hay que apreciarlo más. Como un cantante que anuncia estar engripado para que así el respeto ante su presentación (sin embargo, algo defectuosa) se acreciente.

El segundo es que ha logrado establecer con el pueblo una relación en la que este la cuida paternalmente, y por ello la consiente, o la admira sin preocuparse por comprenderla a cabalidad, así como un padre orgulloso presiente que su hijo se le parece aunque no sepa precisar el cómo ${ }^{20}$. Aquí lo curioso es que Josefina pretende ser ella la que cuida del pueblo, un pueblo ratonil que por supuesto lleva una vida difícil, enfrentado a múltiples enemigos, y que ella cree alentar y sostener en sus interminables esfuerzos de supervivencia. El narrador descree de tal: el arte épico no obtiene un lugar en la sociedad porque produzca valor; más bien, se trata de que el valor preexistente se aprecia a sí mismo a través del arte épico. Por supuesto, sin este no habría manera de saberse valeroso, y por ello se le aprecia con razón.

El tercer aspecto tiene que ver con el hecho de que, precisamente a causa de las extremadamente dificultosas condiciones de vida del pueblo ratonil, este no tendría humor para incluir entre sus ocupaciones el disfrutar de una música realmente elaborada. "No está la Magdalena para tafetanes", se le podría espetar a un hipotético ratón verdaderamente dotado para realizar un arte de gran elegancia y elaboración. Así, Josefina logra, con sus torpes ruiditos, el representar auténticamente a su sufrido pueblo: “...el tenue chillido de Josefina en medio de esos momentos de graves decisiones es casi como la miserable existencia de nuestro pueblo en medio del tumulto del mundo hostil" (Kafka, 2001: 196).

El cuarto aspecto se relaciona con la puerilidad del pueblo ratonil y, al mismo tiempo, con su envejecimiento prematuro. Resulta que los ratones prácticamente no tienen infancia, obligados como viven a tomar urgentemente responsabilidades que aseguren su trabajosa supervivencia y agobiados por una fecundidad imparable que les da nuevos niños mucho antes de que las generaciones previas hayan dejado de serlo. Por ello, un resabio de conducta infantil los acompaña siempre, como un faltante en su experiencia de vida que les pasa una pequeña factura para compensarse a diario. También por su relación peligrosa con el mundo amenazante, los ratones envejecen prematuramente y se acostumbran a la adultez y se cansan de ser viejos, y entonces, junto con esa nostalgia pueril, hay una personalidad renuente a dejarse ir a lo que se considera una frivolidad dadas las circunstancias: un arte de verdad. El de 
Josefina se tolera, entonces, porque en realidad no lo es: son meros chillidos. El niño escondido que hay en todo ratón se divierte con ellos; el viejo amargado que también hay y que no soportaría la presencia impertinente de un arte ostentoso en medio de la batalla, llega a admitir su efecto benéfico. (Vemos que en realidad esto del envejecimiento prematuro es una variante del tercer aspecto, aquí expuesta en conjunto con la puerilidad ratonil, que no se había tratado antes).

El quinto aspecto es quizás el más sutil de todos. Pues en el chillido de Josefina se halla una liberación de los grilletes de la vida cotidiana que permite al pueblo soñar: la situación en la que se emite -que no el chillido mismo- posibilita una experiencia de introspección satisfactoria para el público: "Aquí, en los breves intervalos entre las luchas, el pueblo sueña; como si los miembros de cada individuo se distendieran, como si por una vez el sufriente pudiera tenderse y reposar en el vasto y cálido lecho del pueblo. Y en medio de esos sueños resuena intermitente el chillido de Josefina; ella lo llama canto perlado; nosotros, tartamudeo; pero, de todos modos, ese es su lugar apropiado, más que en cualquier otra parte; casi nunca encontrará la música momento más adecuado. Algo hay allí de nuestra pobre y breve infancia, algo de una dicha perdida que no puede encontrarse más; pero también algo de nuestra vida activa cotidiana, de sus pequeñas alegrías, incomprensibles y, sin embargo, incontenibles e imposibles de obliterar." (Kafka, 2001: 199). El porqué de esta experiencia tiene que ver con ser y no ser el chillido homologable con el chillido común: es un chillido común el de Josefina, pero al llamar la atención sobre él mediante una situación poco común, todos encuentran en él la oportunidad de profundizar en sí mismos. El arte se da más como resultado de las condiciones pragmáticas de su producción que por los valores intrínsecos que pudiera poseer.

$\mathrm{Si}$ quisiéramos condensar los cinco aspectos, diríamos: el efecto estético se produce porque el chillido común se aleja de la circunstancia cotidiana, creándose así un extrañamiento que posibilita la interiorización por parte del receptor del chillido en términos de valoración personal sumamente emotiva (le recuerda su valentía, sus alegrías, su infancia perdida, también su triste circunstancia vital...), una suerte de iluminación íntima y total.

Josefina, para quien el reconocimiento resulta ser lo más importante, es en apariencia quien más ignora estos pormenores acerca de su arte. Lo que ella sabe, lo que ella vive, opera independientemente de todo esto; hay incluso no poca mezquindad y bastante egoísmo en las exigencias de la ratona, que pretende obtener la exención de cualquier otro trabajo ajeno a su música y que no se perturba porque a menudo sus conciertos ponen en riesgo a muchos, en tanto ella permanece a salvo. El pueblo, que la aprecia y a veces incluso la idolatra, se niega en cuanto a darle el privilegio demandado: no se le olvida a Kafka que el arte actúa de muchas formas, pero no como un substituto aceptable de los bienes materiales. El arte es el arte y el mundo es el mundo, y en este, lo material es lo que cuenta. Josefina se engaña al creer posible que el mundo se subordine al arte, y por ello, empecinada en conseguir su exención del trabajo, deja de cantar. Pero el lamento que se deja escuchar en consecuencia no es demasiado fuerte, y la razón es que ya se sospechaban los ratones que la escuchaban que el efecto de su arte se podía asimilar al efecto del silencio, lo que la hacía bastante prescindible como individuo concreto: es una actitud, derivada de una situación, lo que se podría perder al no estar ella, pero también es posible reencontrar esa actitud por otros medios, incluso silenciosos, ya que en el fondo la actitud como tal no depende propiamente de Josefina. Así, cuando al final se dice (este homenaje es arma de dos filos) que "Josefina es inmortal", lo que se está planteando es que el efecto que ella ha provocado se puede seguir produciendo después de la muerte de Josefina.

Pues se trataba desde el principio de que la actividad particular de Josefina, que esta y algunos de sus seguidores creen perdurable, no es más que otro paso hacia el innumerable olvido, un acercamiento inevitable a la nada que todo lo traga. Nadie tiene un lugar de privilegio en relación con esta verdad, y los ratones (a quienes no les interesa la historia porque poseen una acrecentada conciencia de su provisionalidad 
en el mundo) lo saben bien. A Josefina le convendría recordar a Borges y su poeta menor: "La meta es el olvido. Yo he llegado antes." El artista debería saberse uno con su pueblo, dado que en el fondo lo es, por la incontenible verdad de la nada que los habrá de asimilar en la vastedad del tiempo.

\section{En conclusión}

El arte actúa sin que la soledad del artista se vea amainada por ello. Este irá tras sus objetivos: el supremo es la muerte como culminación de un proceso irremediable. Por sus veleidades (deseo de fama, de confort o de reconocimiento), puede que persiga otras cosas, pero sólo será un verdadero artista quien mire a la muerte mientras esté creando. Sabido esto, el público vendrá a ser más bien una molestia necesaria, y en el mejor de los casos, el artista encontrará un público y un empresario paternales que lo protegerán dada su extrema debilidad, resultante directa de un arte que es inducción a la muerte. El arte que nutre debilita al cuerpo, al hacerlo cada vez más próximo a un espíritu que, sin embargo, sin el cuerpo se muere o, al menos, a lo que podemos ver, desaparece.

El artista es uno con el pueblo en relación con su fin trágico. También vive en circunstancias difíciles, como todo el mundo, aunque aquí los grados de atenuación sí dependen directamente de cuán apreciado o despreciado sea. Pero, como rasgo distintivo, el artista es quien ha hecho de su destino mortal una meta que debe ir elaborando y exhibiendo; la exhibición sin embargo parece ocurrir ya sea por vanidad, ya sea porque resulta inevitable al artista el contar con alguna red social de la cual formar parte, pero nunca porque el artista confíe en poder ser comprendido por el público. Aquí hay hesitación entre las posibilidades, seguramente la misma duda que hizo de Kafka un autor que a veces publicó, pero que en el lecho de muerte pidió se incinerasen sus escritos, que por cierto bien pudo haber quemado él mismo de previo si su decisión hubiera sido tajante.

El destino del artista es la insatisfacción. Nunca su arte le será completamente satisfactorio, como no sea tal vez (pero no es posible que se nos informe sobre el particular) en su lecho de muerte. El destino del artista también es la incomprensión, independientemente del éxito que conozca o ignore. Lo apreciarán sin darse cuenta de que jamás consigue lo que en verdad quiere; lo despreciarán sin percatarse de su pureza. Lo único que cambia (que no es poco, pero tampoco es lo fundamental) es la humillación a que se ve sometido el artista cuando no lo aprecian.

No obstante tamaña incomunicación, el arte producirá, cuando resulte bien, un efecto sobre las personas. Estas lograrán intimar consigo mismas gracias a su aproximación al arte. Este sabrá iluminar un proceso de interiorización en el que toda la existencia se visualizará conjuntamente, en forma contradictoria y al mismo tiempo maravillosa. La incomprensión no se supera, pero eso casi no importa, porque una mala comprensión puede ser, y es en muchas ocasiones, una experiencia notable y espléndida. Habrá entonces un paradójico "malentendido provechoso". Y, cuando el arte no resulte bien, al menos no producirá mayor daño (salvo al pobre $\operatorname{artista}^{21}$ ), sino mera indiferencia en el público.

Kafka tiene una justa fama de autor pesimista. Pero no todas son malas noticias: el malentendido estético produce frutos fugaces pero deliciosos en su camino a la muerte. El arte ocurre. Siempre que no se lo queme. Y quizás, de un modo enigmático, también cuando arde en las llamas.

\section{Notas}

1. Véase Herra 2007, p. 9.

2. América debe rebautizarse como El desaparecido. Pero uso aquí el nombre todavía más conocido.

3. Incluso, en alguna medida, su correspondencia y sus diarios.

4. Usaré la versión de un traductor insigne: Jorge Luis Borges. 
5. Es bien sabido que fue y vino varias veces de compromisos matrimoniales que primero ejecutaba y luego lamentaba.

6. Cabe la posibilidad de que quisiera cumplir ante sí mismo más que ante alguien más. Pero se trataba de "cumplir", al fin: como artista no tenía que obligarse de ningún modo a hacer arte, se le daba inexorablemente.

7. Uso la versión francesa de las cartas a Felice, que me parece mucho mejor que la castellana de que dispongo.

8. Siendo quien es el traductor con el que trabajo, no creo que haya elegido los términos menos cuidadosamente que el propio Kafka.

9. Vale decir que, verdad de Perogrullo, vive una existencia temporal.

10. Borges propone que Kafka se sintió defraudado por su propia obra dado que esta era fuente de "tristezas y postergaciones", en lugar de ser un afirmador acto de fe. (Véase la introducción a Kafka 1985, p. 10) Disiento de esta opinión sólo en el tanto se quiera entender que es una fe judía lo perseguido (y Borges así lo afirma); la suscribo, si se trata de una fe en la belleza, una fe en la posibilidad vivencial del acto estético.

11. La cita se puede extender, aunque, como no es lo que principalmente nos ocupa, queda relegada su continuación a esta nota: "El hecho de que, en apariencia, haya tantos que lo consiguen fácilmente no demuestra lo contrario, porque, en primer lugar, no son tantos los que lo consiguen de verdad, y, en segundo lugar, esos pocos, por lo general, no lo 'hacen' sino que simplemente les 'ocurre'; no llega a ser aquel 'máximo' de que te he hablado, aunque sigue siendo algo muy grande y honroso (en especial porque el 'hacer' y el 'ocurrir' no pueden diferenciarse netamente)." (Kafka, 1984: 54-55) En el contexto de la carta, la intención de este pasaje es clara. Kafka acusa al padre de no haber conseguido de verdad el ser un padre de familia, pues no ha cumplido como guía, y si alguna vez lo ha sido, ello le ocurrió, sin que fuese enteramente consecuencia de sus méritos.

12. Trabajo otra vez con una traducción de Jorge Luis Borges.
13. Cuarenta días, un ayuno de cuarenta días... La connotación religiosa salta a la vista, pero más me parece una "cáscara de banano" dejada por Kafka que una verdadera pista para orientar la lectura. Kafka podía ser bastante bromista.

14. Alguno es de la talla de Harold Bloom, quien acusa a Kafka de ser mucho más brillante al iniciar relatos que al concluirlos. Véase Bloom 1994, p. 458.

15. Aclaro aquí que mi intención no es indagar en las profundidades psicológicas de por qué Kafka solicitó la quema de sus libros; ello pudo deberse a tantas cosas que en rigor habría que incluir hasta el delirio o la depresión. Persigo más bien hablar de las concepciones estéticas de Kafka que podrían fundamentar el ocultamiento de la producción artística, tanto la propia como eventualmente la ajena.

16. Se me podría indicar entonces que los mayores artistas, más rápidos incluso que el ayunador, son los suicidas. Discrepo: el suicida pasa por alto la necesidad que tiene el arte, para existir, de crear un proceso. Otra cosa sería pensar que los mayores filósofos son los suicidas; este tema lo discute Camus en El mito de Sísifo.

17. La traducción es de J.R. Wilcock. En Kafka 2001, pp. 185 ss.

18. Claro que, rigurosamente, comprensión errónea sería igual a incomprensión. Pero concédaseme momentáneamente la licencia de pasar esto por alto.

19. La paradoja en Kafk -cualquiera lo nota- es la expresión más cabal del universo.

20. Por cierto que el empresario que cuida al artista del trapecio también se ajusta a ese rol paternal y protector.

21. Que no parezca que juzgo las humillaciones por las que pasan los artistas (kafkianos y no kafkianos) como una pequeña cosa: son algo terrible para el artista, sólo que no esencialmente dañino para el arte, cuyos problemas relevantes están en otras partes.

\section{Bibliografía}

Bajtín, Mijaíl. 1988. Problemas de la poética de Dostoievski. (Traducción de Tatiana 
Bubnova) Fondo de Cultura Económica, México.

Blanchot, Maurice. 1981. De Kafka a Kafka. Gallimard: Paris.

Bloom, Harold. 1995. El canon literario. Traducción de Damián Alou. Anagrama: Barcelona.

Borges, Jorge Luis. 1987. Obra poética 19231977. Alianza: Madrid.

Camus, Albert. s.f. El hombre rebelde. Alfa Omega: Santo Domingo.

Camus, Albert. 1983. El mito de Sísifo. Alianza, Madrid.

Deleuze, Gilles y Félix Guattari. 1978. Kafka. Por una literatura menor. Traducción de Jorge Aguilar Mora. Ediciones Era: México, D.F.

Dodd, W.J. 1992. Kafka and Dostoievsky. The Shaping of Influence. St. Martin's Press: London.

Dostoievski, Fédor. 1964. Crimen y castigo. Traducción de José Fernández. Editorial Juventud: Barcelona.

Dostoievski, Fédor. 1983. Los hermanos Karamázov. Traducción de Augusto Vidal. Bruguera: Barcelona.

Eco, Umberto. 1995. Semiótica y filosofía del lenguaje. Lumen: Barcelona.

Eco, Umberto. 1999. Arte y belleza en la estética medieval. Lumen: Barcelona.

Eco, Umberto. 1975. Obra Abierta. Lumen: Barcelona.
Eco, Umberto. 1981. Lector in Fabula. Lumen: Barcelona.

García Márquez, Gabriel. 1993. El olor de la guayaba. Conversaciones con Plinio Apuleyo Mendoza. Editorial Diana: México, D.F.

Gutiérrez, Claudio. 2006. Ensayos sobre un nuevo humanismo. Editorial EUNED: San José.

Herra, Rafael Ángel. 2007. Autoengaño. Palabras para todos y sobre cada cual. Editorial Universidad de Costa Rica: San José.

Hitchens, Christopher. 2008. Dios no es bueno. Alegato contra la religión. Debate: México, D.F.

Isaacson, José. 2005. La realidad metafísica de Franz Kafka. Corregidor: Buenos Aires.

Kafka, Franz. 1984. Cartas a Felice. Traducción de J.R. Wilcock. Alianza Editorial: Madrid.

Kafka, Franz. 1992. Obras selectas. Edición de Antonio Massone. Traducción de D.J. Vogelmann. Andrés Bello: Buenos Aires.

Kafka, Franz. 2001. La condena. Traducción de J.R. Wilcock. Alianza Editorial: Madrid.

Kafka, Franz. 1974. Carta al padre. Traducción de Feliu Formosa. Lumen: Barcelona.

Kafka, Franz. 1985. El buitre. Selección y prólogo de Jorge Luis Borges. Emecé: Madrid.

Kafka, Franz. 1981. El castillo. Traducción de J. A. Moyano Moradillo. EDAF: Madrid.

Kafka, Franz. 1982. América. Traducción de D.J. Vogelmann. Alianza Editorial: Madrid. 
Lombardo Radice, Lucio. 1977. El acusado Kafka. Icaria: Barcelona.

Murray, Nicholas. 2006. Kafka. Literatura y pasión. Traducción de Silvia Kot. El Ateneo: Buenos Aires.

Sánchez Trujillo, Guillermo. 2004. Crimen y castigo de Franz Kafka. Libros en red: United Kingdom.
Todorov, Tzvetan. 1991. Crítica de la crítica. Paidós, Barcelona.

Wagenbach, Klaus. 1969. La juventud de Franz Kafka. Traducción de Roberto J. Vernengo. Monte Avila Editores: Caracas.

Wilde, Oscar. 1952. El retrato de Dorian Gray. Traducción de Ricardo Baeza. El Ateneo: Buenos Aires. 
